\title{
Fault Ride-Through Study of Wind Turbines
}

\author{
Xinyan Zhang ${ }^{1}$, Xuan $\mathrm{Cao}^{2}$, Weiqing Wang ${ }^{1}$, Chao Yun ${ }^{1}$ \\ ${ }^{1}$ School of Electrical Engineering, Xinjiang University, Urumqi, China; ${ }^{2}$ School of Electronics Information Engineering, China Civil \\ Aviation University, Tianjin, China. \\ Email: xjcxzxy@126.com
}

Received September 2013

\begin{abstract}
The installation of wind energy has increased rapidly around the world. The grid codes about the wind energy require wind turbine (WT) has the ability of fault (or low voltage) ride-through (FRT). To study the FRT operation of the wind farms, three methods were discussed. First, the rotor short current of doubly-fed induction generator (DFIG) was limited by introducing a rotor side protection circuit. Second, the voltage of DC bus was limited by a DC energy absorb circuit. Third, STATCOM was used to increase the low level voltages of the wind farm. Simulation under MATLAB was studied and the corresponding results were given and discussed. The methods proposed in this paper can limit the rotor short current and the DC voltage of the DFIG WT to some degree, but the voltage support to the power system during the fault largely depend on the installation place of STATCOM.
\end{abstract}

Keywords: Wind Energy; Fault Ride-Through; Doubly-Fed induction Generator; Wind Farm

\section{Introduction}

Large scale of wind power has been installed in every where around the world. Both the wind farm installation capability and the WT capacity have increased rapidly. Although the time start to use of wind power in China is very late, the development is very fast. There were many constant speed wind turbines (CSWT) using stall control with squirrel cage induction generators (SCIG) installed in the wind farms in China. Newly installed WTs are dominated by variable-speed wind turbines (VSWT) using pitch control with DFIG. VSWT with direct-driven permanent-magnet synchronous generator (DDPSG) has been successfully studied and installed. Now the 6MW DDPSG WT used for the offshore wind farm has being developed. The wind power capacities installation in China has increased very rapidly. Figure $\mathbf{1}$ is the wind power capacities installation in one province of China.

Power system operation with increasing wind power penetration will become more and more difficult. More conventional power plants will be replaced by wind farms and accordingly the stability of the power system will be affected. So the new grid codes have proposed even strict requirement to the wind power. Not only the wind turbines should be kept connection in grid during the fault and fast recover power generation after fault clearance, but also the wind turbines or wind farm can provide the voltage support and generate capacitive reactive power [1]. To meet this requirement, there are many researchers put their study on this subject. The studies can be mainly divided into three categories. The first one is mainly concern about the protection of the rotor side converter of DFIG WT during the fault. Paper [2] has given a through discussion about the operation process of the rotor side crowbar of DFIG WT. Paper [3] has provided a method to improve the vector control and limit the rotor current. Paper [4] has proposed a new magnet excitation method to counteract the transient DC flux. The second one is mainly concern about how to make the wind turbine fast recover power generation after the fault clearance. Paper [5] has discussed some methods to protect the VSWT with DFIG and DDPSG and their fast recover power generation capabilities. Paper [6] has studied the double vector control method. Paper [7] has made a detail study of the post-fault behavior of the power system with wind power connected. The third one is mainly concern the voltage and reactive power support to the power system during the fault. Paper [8] has provided a rotor side converter reactive control. Paper [9] has discussed the DDPSG WT FRT methods under unity, leading and lagging power factor respectively. There are new publications, as discussed in paper [10-12] also give some suggestions and simulation results about the fault ride-through of wind turbine generator systems.

The rotor current and DC voltage limitation is mainly discussed in this paper. The method to give a voltage support to power system by using STATCOM in the wind farm is also proposed here. 
Wind Power Capacity Installation in Xinjiang of China 2000-2012

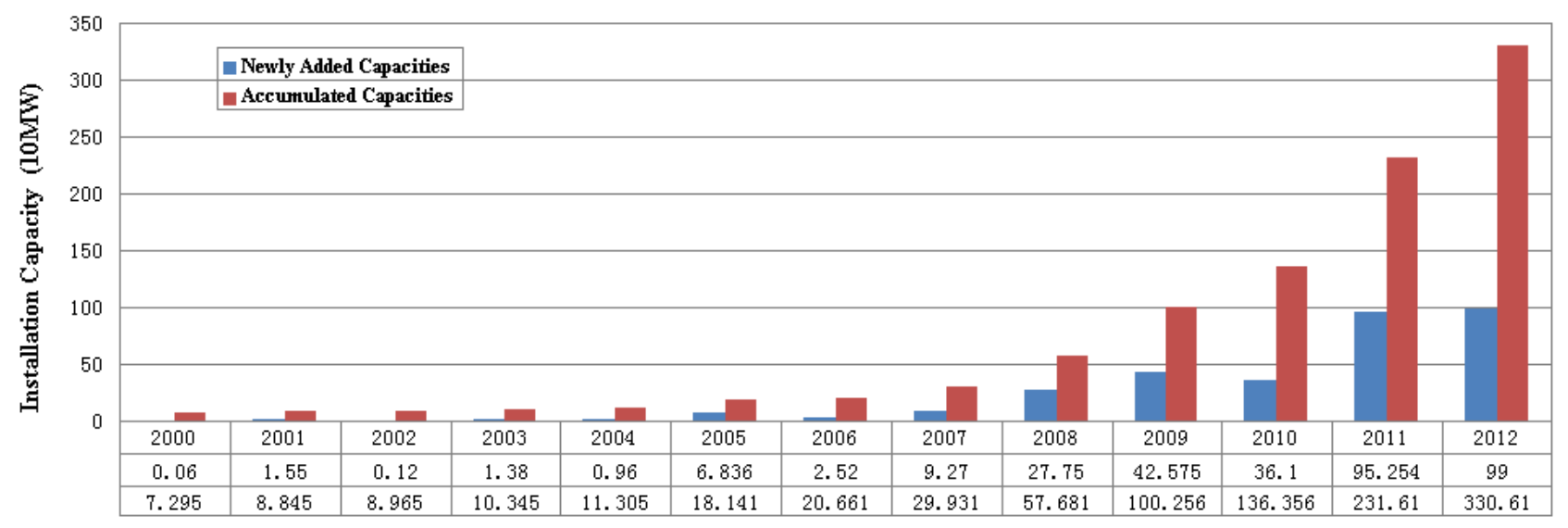

Figure 1. The WTs installation capabilities in Xinjiang of China.

\section{Fault Ride-Through Requirement of WTS}

The increasing and expansion of wind power has set some new problems to power system. The power system with large scale wind power will involve problems not only in steady state operation but also in contingency condition. FRT requires keep the WTs on the grid during faults so that they can contribute to the stability to the power transmission system. Experts have done many researches about the behaviors of WTs. Figure 2(a) gives the simulation results of the behavior of induction generator based on WT following grid faults. We can find after $250 \mathrm{~ms}$, if the fault still can not be cleared, it will lead to voltage collapse. Figure 2(b) is the basic requirements of fault ride-through of E.ON of Germany. In the second (blue) area, the WTs should be kept on grid, but if the WTs face overloads and stability problems, they can short time interrupt (STI), but the STI time must be far less than 2 s.

\section{Protection Measure Study of WT for FRT}

Voltage drop is the most common fault occurred in the power system. The depths of the voltage sags are different according to the place where the fault occurrence. The lowest depth of voltage sag can be zero. To meet the requirement of grid for FRT of WTs, WT must keep in grid while there is a fault in the power system, such as single-phase ground, three-phase ground, etc. Nowadays, the majority WTs use DFIG as electrical power generator. The stator of DFIG is directly connected to the grid, while its three-phase rotor windings are coupled to the grid through a back-to-back partial size (about 20\% - 30\% of the rated power of DFIG) converter. A short circuit within the grid may lead to a 5 - 8 times of the rated stator current of DFIG. So the mechanical drive and shaft will subject to a considerable stress. And the very high rotor current may lead to the rotor side converter damage

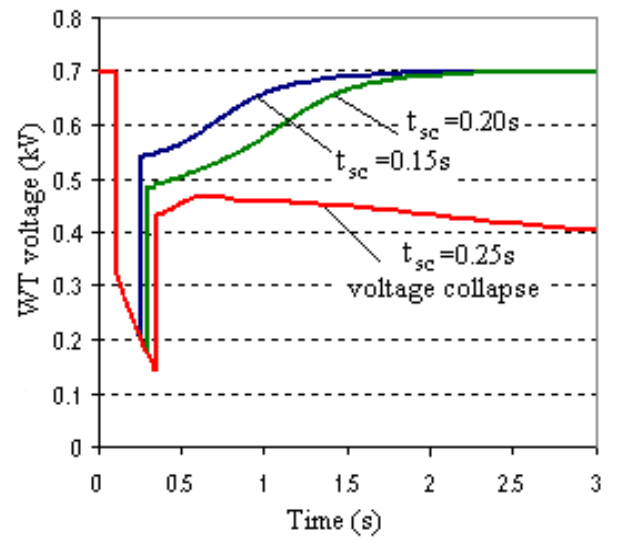

(a)

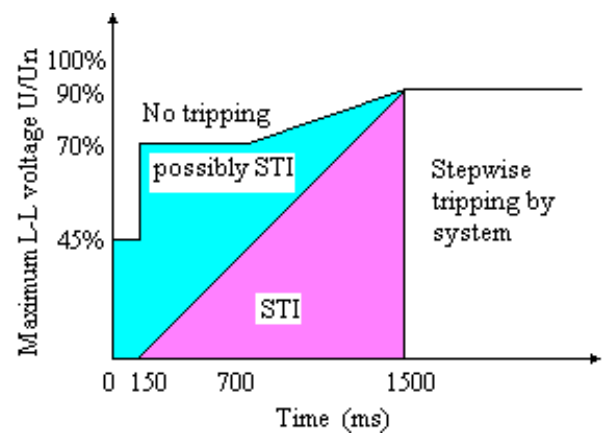

(b)

Figure 2. The voltages under fault and FRT requirement, (a) the voltages under fault with different fault clearance times, (b) boundary conditions for FRT requirement.

and the DC bus over-voltage. Therefore, most measures are proposed to protect the converter and DC bus. Actually, the stator will also endure a high transient current. At present, the protection circuit of VSWTs with DFIG mainly includes three parts. They are rotor side crowbar, DC bus chopper and stator side crowbar used to protect rotor side converter, DC bus and the DFIG. In this section, we major discuss the rotor side and DC bus protec- 
tion. The block diagram is shown in Figure 3.

\subsection{The Rotor Side Protection Measure}

During the fault of the power system, the stator of DFIG will endure a large fault current because it is directly connected to the grid. The disturbance will be further transmitted to the rotor of DFIG for the reason that the rotor and stator is magnetically coupled and the flux must be conservative. So the rotor current will be very high and this may lead to over current to the rotor side converter. We use IGBT and resister to make an over current limiter (shown in Figure 3) to protect the rotor side converter. Figure 4(a) gives the simulation results of rotor current. We can find that use the limiter, the rotor current can be limited within the rated range.

The DC voltage with and without rotor side over current limiter are shown in Figures 4(b) and (c) respectively. The simulation result shows that if there is not rotor current limiter, the DC voltage will be $1275 \mathrm{~V}$ when the fault occur and it will be $1273 \mathrm{~V}$ when the fault is just cleared; if there is the current limiter, the DC voltage can be dropped in some degree, the value is $1260 \mathrm{~V}$ when the fault occur and is $1242 \mathrm{~V}$ when the fault is just cleared. So there is still a $5 \%$ over voltage.

\subsection{The DC Bus Protection Measure}

Use When the fault (short circuit) occurs, the voltage will drop considerably and the depth is zero in the place where the fault is located. In the fault moment, the grid side converter (GSC) lost its ability to transfer the power from the rotor side converter (RSC) to the grid, but the WT is still driven by the wind energy, so there will be a lot of energy gathered in the DC part of the back-to-back power electronic converter. This will make the DC capacitor be over charged and consequently the voltage of the DC bus will be very high. Use the rotor current limiter, the transient over current can be reduced, this will lead to the drop of the DC over voltage. But just as discussed in subsection A of this section, the DC bus still has a considerable over voltage. So we introduce a DC voltage limiter by using the chopper shown in Figure 2 to absorb the additional energy. Figure 5 shows the simulation result of the DC voltage while the DC over voltage limiter is used. It can be found the over voltage has been reduced from $1300 \mathrm{kV}$ to $1235 \mathrm{kV}$, but there is still $3 \%$ at the moment when the fault is cleared. And the voltage drop can not be removed.

\section{Voltage Support}

Conventional synchronous generator is able to supply high short-circuit current to the fault location and holds the voltage in the power system so the low voltage area be reduced. As the increasing of the wind power penetra-

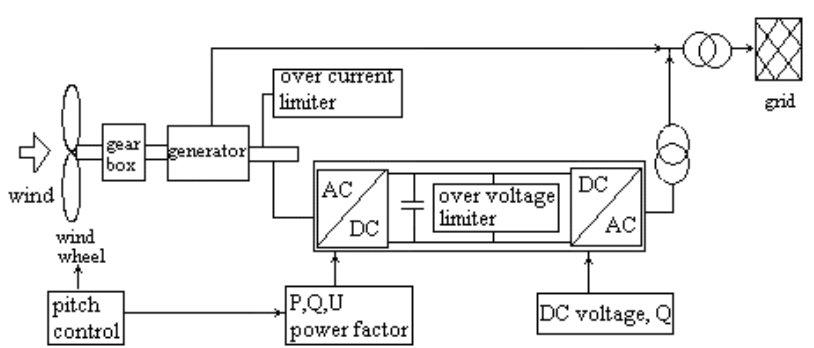

Figure 3. The block diagram of protection measure for FRT of DFIG WT.

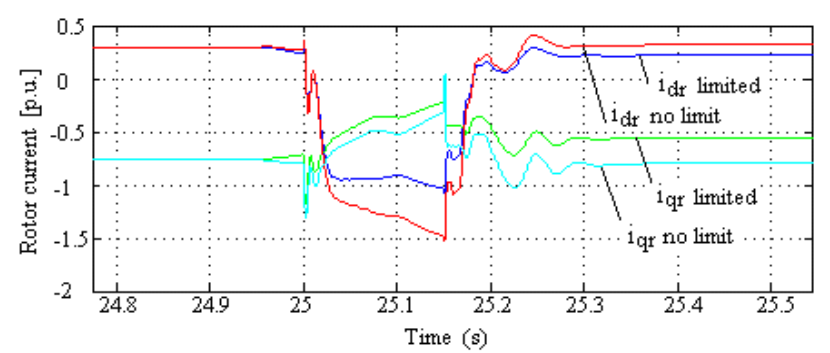

(a)

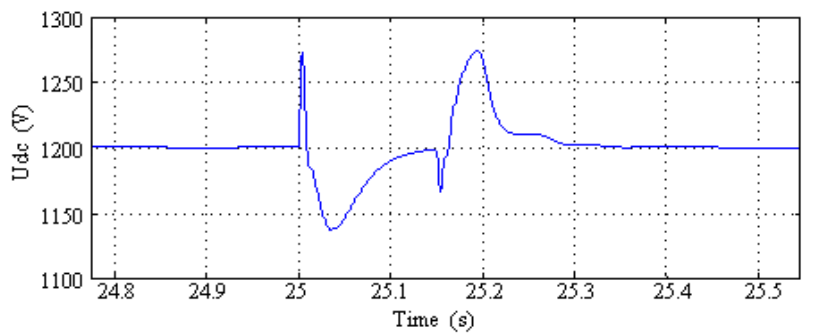

(b)

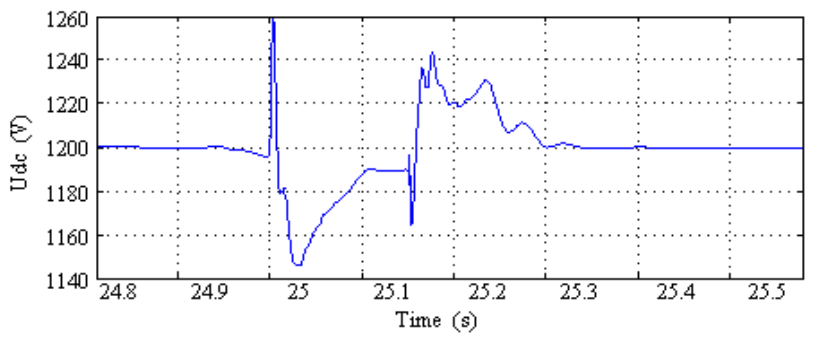

(c)

Figure 4. The simulation results of rotor current and DC voltage of DFIG WT, (a) the rotor current during fault; (b) the DC voltage without rotor current limitation; (c) the DC voltage with rotor current limitation.

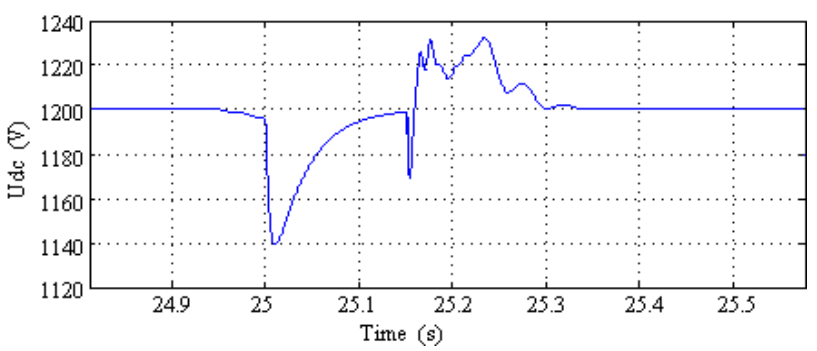

Figure 5. Simulation result of the DC voltage with DC over voltage limiter. 
tion in power system more and more conventional power will be replaced by the wind power. So the wind farm must have the ability to give the power system voltage support during the fault condition. There are some researches in this aspect. One is major in study how to control the reactive current and then let the WT has the ability to generate reactive power. The other is major in how to improve the voltage of the wind farm and give reactive power to the system at the same time. Because the reactive power generated by the WT is limited, more attention now is drawn to improve the voltage by use FACTS, especially in the condition that the wind farm is built by SCIG WTs for the reason that this kind of WTs can not generate reactive power by the control within the generator.

We use a simplified system of a power system with wind farm shown in Figure 6 to study the voltage support of the wind farm by using STATCOM, because STATCOM not only can improve the voltage level but also can generate both lagging and leading reactive power. In Figure 6, LV means low level voltage, MV means middle level voltage, $\mathrm{HV}$ means high level voltage.

Figure 7 shows the simulation result when the wind farm is built by DFIG WTs.

From Figure 7(a), we can find using STATCOM the absorbed reactive power can be reduced, especially at the moment that the fault is occurred and cleared. Figure 7(b) shows the LV voltage condition while there is fault. From this result, we find the voltage can be increased. But at the moment the fault is cleared, the voltage has more than $10 \%$ over voltage. Figure 7 (c) shows the LV voltage condition while there is serious voltage dip. From this result, we find the voltage can be increased to $90 \%$ of the rated voltage level. But at the moment the fault is cleared, the voltage has also nearly $10 \%$ over voltage. About this problem we need further study in future.

Figure 8 shows the simulation result when the wind farm is built by SCIG WTs.

Figure 8(a) shows the LV voltage and MV voltage when there is fault occurred in the power system; Figure 8(b) shows the voltages of LV bus and MV bus while the STATCOM is connected in the MV bus during the fault; Figure 8(c) shows the voltages of LV bus and MV bus while the STATCOM is connected in the LV bus during the fault. From the simulation results, we can find using STATCOM the voltages of both LV bus and MV bus can be increased. But the voltage amplitudes increased are different according to the place where STATCOM located. STATCOM connected to the LV bus is better for the wind farm.

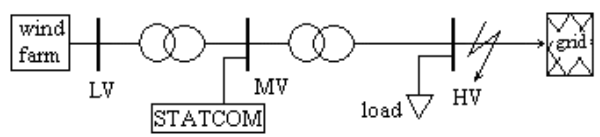

Figure 6. The power system with wind farm.

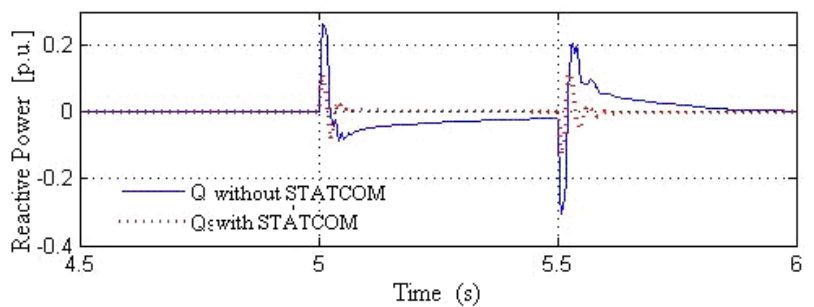

(a)

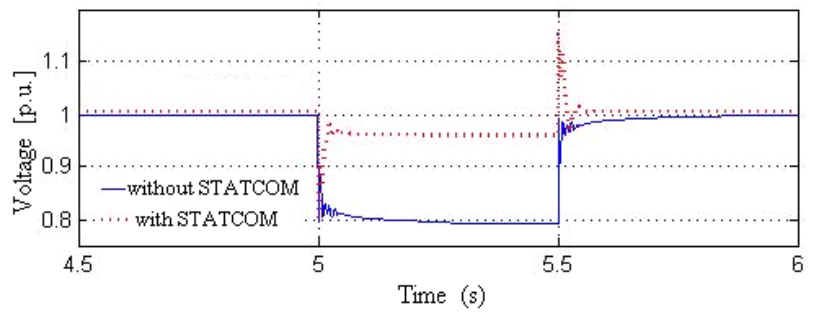

(b)

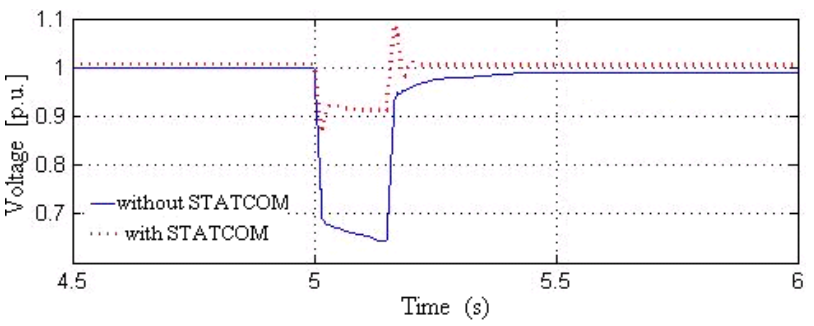

(c)

Figure 7. Simulation result under fault condition when the wind farm is built by DFIG WTs, (a) the reactive power of the wind farm during the voltage dip, (b)the $L V$ voltage of the wind farm during the serious voltage dip.

\section{Conclusion}

The power system fault will lead to voltage dip on WTs. To maintain the grid stability, wind farm is required to keep connected in the power system for a defined time period under grid fault, this is called FRT. Actually, the voltage is not always dip to zero, it can be just a voltage sag. So many researchers put their efforts to deal with the so called low voltage ride-through problem. The main differences in FRTs requirement of different countries are the depth of voltage drop, the time period and the boundary where WTs can be tripped. New FRT needs not only the WTs keep on grid but also can provide voltage support or generator reactive power to the power system. So nowadays, the FRT researchers care even more subjects. How to protect the converter and DC bus of WTs, how to control the generator to generate reactive power and how to increase the voltage under grid fault are the three main study directions.

\section{Acknowledgements}

The work is supported by NSFC of Xinjiang of China (No. 2011211A016) and Doctor Project of Xinjiang Uni- 


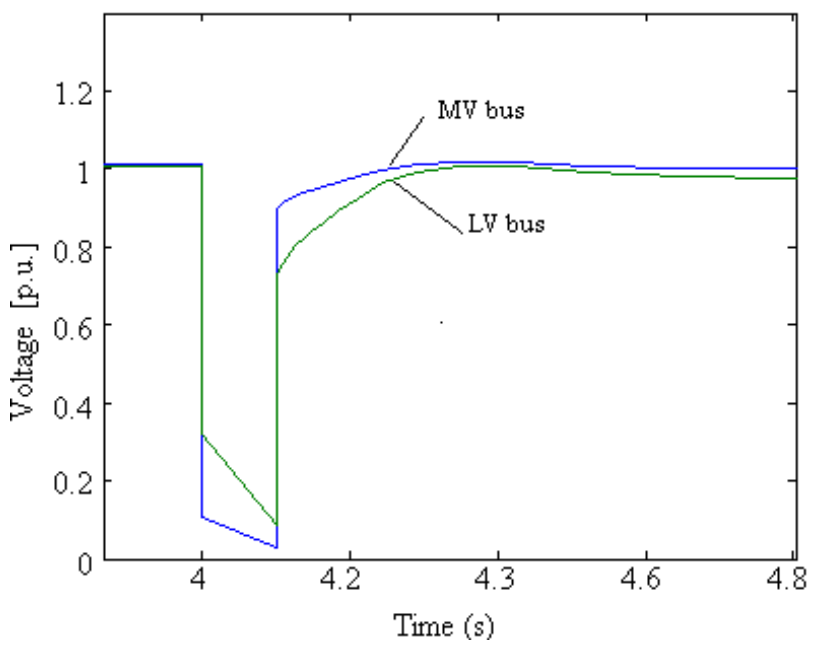

(a)

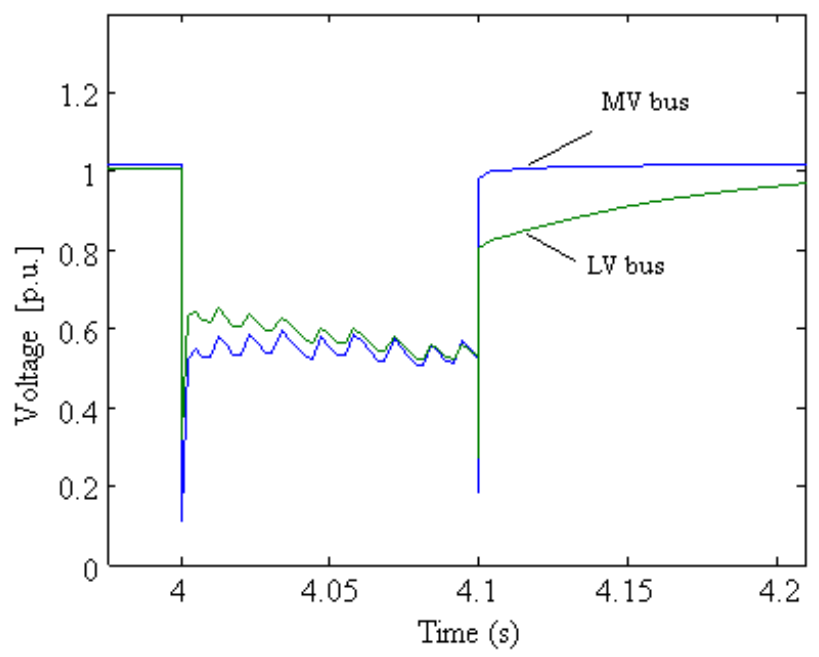

(b)

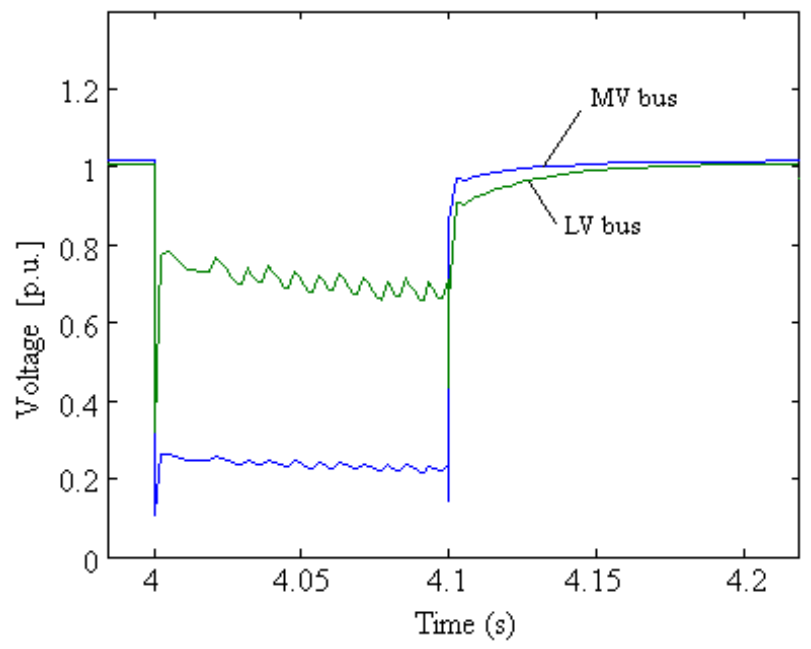

(c)

Figure 8. The LV and MV voltage of system shown in Figure 6 under fault when wind farm is built by SCIG WTs, (a) without STATCOM, (b) STATCOM connected in the MV bus, (c) STATCOM connected in LV bus. versity (No. BS100122).

\section{REFERENCES}

[1] I. Erlich, W. Winter and A. Dittrich, "Advanced Grid Requirement for the Integration of Wind Turbines into the German Transmission System,” IEEE Powertech Conference Proceedings, St. Petersburg, Russia, 27-30 June, 2006, pp.1210-1216.

[2] A. D. Hansen and C. Michalke, "Fault Ride-through Capability of DFIG Wind Turbines," Renewable Energy, Vol. 32, No. 8, 2007, pp. 1594-1610. http://dx.doi.org/10.1016/j.renene.2006.10.008

[3] J. B. Hu, D. Sun, Y. K. He and R.-D. Zhao, "Modeling and Control of DFIG Wind Energy Generation System under Grid Voltage Dip", Automation of Electric Power Systems, Vol. 30, No. 8, 2006, pp. 21-26.

[4] D. W. Xiang, S. C. Yang and L. Ran, "Magnet Excitation Control Strategy of DFIG on Grid Operation during Power System Symmetric Fault,” Proceedings of the CSEE, Vol. 26, No. 3, 2006, pp. 164-169.

[5] S. J. Hu, J. L. Li and H. H. Xu, "Analysis on Protection Circuits Suitable for VSCF-WECS to Cope with Grid Faults," Commutation Technology and Power Draw, No. 1, 2008, pp. 45-50.

[6] X. P. Zhang, "Performance of PWM Rectifier under Voltage Dips in Wind Power," Electrical Application, Vol. 28, No. 9, 2007, pp. 52-56.

[7] C. Jauch, P. Sorensen, I. Norheim and C. Rasmussen, "Simulation of the Impact of Wind Power on the Transient Fault Behavior of the Nordic Power System,” Electric Power System Research, Vol. 77, 2007, pp. 135-144.

[8] I. Erlich, C. Feltes, F. Shewarega and M. Wilch, "Interaction of Large Offshore Wind Parks with the Electrical Grid,” Proceedings of DRPT 2008, Nanjing, China, 3-5 April, 2008, pp. 1242-1250.

[9] S. J. Hu, J. L. Li and H. H. Xu, "Analysis on the LowVoltage-Ride-Through Capability of Direct-Drive Permanent Magnetic Generator Wind Turbines,” Automation of Electric Power Systems, Vol. 31, No. 17, 2007, pp. 73-77.

[10] D. Campos-Gaona, E. Moreno-Goytia and O. Anaya-Lara, "Fault Ride-Through Improvement of DFIG-WT by Integrating a Two-Degrees-of-Freedom Internal Model Control," IEEE Transactions on Industrial Electronics, Vol. 60, No. 3, 2013, pp. 1133-1145.

[11] R. L. Hendriks, R. Völzke and W. L. Kling, "Fault RideThrough Strategies for VSC-Connected Wind Parks," Europe's Premier Wind Energy Event, Marseille, France, 16-19 March 2009, pp. 252-260.

[12] A. Arulampalam, G. Ramtharan, N. Caliao, J. B. Ekanayake and N. Jenkins, "Simulated Onshore-Fault Ride through of Offshore Wind Farms Connected through VSC HVDC," Wind Engineering, Vol. 32, No. 2, 2008, pp. 103-113. 